\title{
Phytoplankton Community Investigation and Water Quality Assessment of M River in winter in Shijiazhuang City
}

\author{
Ziqi Zhang ${ }^{1}$, Lei Yang ${ }^{2}$, Dongxu Han ${ }^{3,4}$, Hongyan Shen ${ }^{3,4, *}$ \\ ${ }^{1}$ School of Materials Science and Technology, China University of Geosciences Beijing, Beijing, 100083 \\ ${ }^{2}$ Department of Quality Inspection and Management, Hebei Chemical and Pharmaceutical College, Shijiazhuang, 050026 \\ ${ }^{3}$ College of Environmental Science and Engineering, Hebei University of Science and Technology, Shijiazhuang, 050018 \\ ${ }^{4}$ Pharmaceutical Molecular Chemistry Laboratory of Hebei Province, Shijiazhuang, 050018
}

\begin{abstract}
An investigation of phytoplankton community and water quality for M River was conducted in December 2019.The results showed that 38 species of phytoplankton belonging to 6 phyla and 26 genera were collected. Among them, Bacillariophyta is the richest species, which accounted for $34.21 \%$, followed by Cyanophyta with $26.32 \%$ and Chlorophyta with $28.95 \%$. The density of phytoplankton was $63.0 * 106$ inds/L which indicated as eutrophic water body. The highest density was Bacillariophyta, accounting for 51.03\%. The Shannon-Wiener diversity index $\left(\mathrm{H}^{\prime}\right)$ varied from 1.34 to 2.24 , the Margalef Species diversity index (d) varied from 2.71 to 3.85 , and the Pielou evenness index $(\mathrm{J})$ varied from 0.38 to 0.67 . According to the integrative analysis results of $\mathrm{H}^{\prime}, \mathrm{d}$ and J, M River water quality belongs to oligo-polluted, but individual sites belong to meso-polluted.
\end{abstract}

\section{Introduction}

The survival of aquatic organisms is closely related to the water environment quality, and the composition of species and their proportion in the community can reflect the water quality ${ }^{[1]}$. Phytoplankton forms the basic link in the food chain of an aquatic ecosystem and virtually all the dynamic features of lakes such as color, clarity, trophic state, zooplankton, and fish production depend to a large extent on the phytoplankton. Freshwater communities are very much sensitive to environmental variables ${ }^{[2]}$. The number of species, dominant species and diversity index of phytoplankton community varied greatly in the water environment with different nutrition levels, which often become a biological index of water environmental monitoring and eutrophication ${ }^{[3-4]}$.

There have been many studies on phytoplankton community investigation and water quality evaluation on surface rivers and watersheds. An investigation was carried out in the Shanxi section of Xiaolangdi Reservoir from May 2014 to November 2015, the result showed that water body of Xiaolangdi Reservoir belongs to medium eutrophication level ${ }^{[5]}$. Phytoplankton community investigation and water quality evaluated were conducted in the three typical waters of Baiyangdian Lake from April to November in 2013, the conclusion is phytoplankton distribution was significantly affected by three environment factors ${ }^{[6]}$. However, there is little research on water quality evaluation for the M River. In this paper, the phytoplankton community constitute and water quality evaluation in M River were carried out in December 2019.
Results of phytoplankton composition together with water quality parameters are reported, which provided the basic data for the ecological environment management.

\section{Materal and method}

\subsection{Overview of the study area}

M River is located in Shijiazhuang City, Hebei Province, a total length of 56.9 kilometers. It is divided into the east, west, south, north and center five rivers around the city, east line for Century Park, west line for Zhongshan Park, south line for the Ouyun Park, north line for Pearl Park, center line for Binhe Park. In turn named S1, S2, S3, S4, S5. The water system of this river is city landscape water body. In recent years, human activities have made a significant impact on the ecological environment of $\mathrm{M}$ River. Therefore, it is necessary to know the water quality of the M River to control and prevent water pollution. In December 2016, samples were collected and analyzed in the S1, S2, S3, S4, S5 (Fig.1).

\footnotetext{
* Corresponding author: 1178611805@qq.com
} 


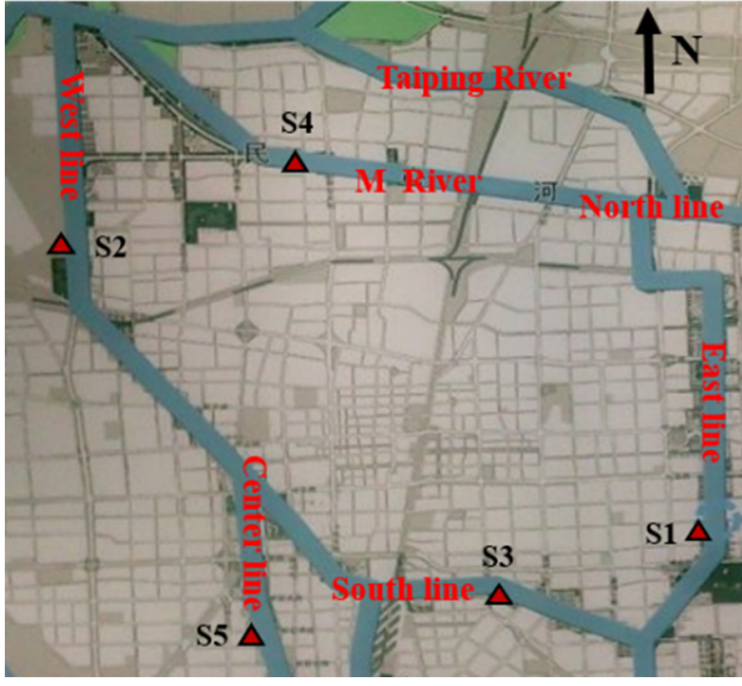

Fig.1 Sampling sites in M River

Tab.1 Latitude and longitude of sampling point

\begin{tabular}{|c|c|c|}
\hline Point & Latitude & Longitude \\
\hline $\mathrm{S} 1$ & $38.020753^{\circ} \mathrm{N}$ & $114.533908^{\circ} \mathrm{E}$ \\
\hline $\mathrm{S} 2$ & $38.067455^{\circ} \mathrm{N}$ & $114.431105^{\circ} \mathrm{E}$ \\
\hline $\mathrm{S} 3$ & $38.016171^{\circ} \mathrm{N}$ & $114.504844^{\circ} \mathrm{E}$ \\
\hline $\mathrm{S} 4$ & $38.083076^{\circ} \mathrm{N}$ & $114.478397^{\circ} \mathrm{E}$ \\
\hline $\mathrm{S} 5$ & $38.000818^{\circ} \mathrm{N}$ & $114.463152^{\circ} \mathrm{E}$ \\
\hline
\end{tabular}

\subsection{Phytoplankton samples}

The samples for phytoplankton analysis were collected using $5 \mathrm{~L}$ plexiglass water harvesting device at the depth of $0 \sim 0.5 \mathrm{~m} .4 \%$ formalin were then added to the phytoplankton samples for longer preservation ${ }^{[7-8]}$. Before taxonomic analyses and species enumeration, the samples for phytoplankton analysis were stored in the dark in evacuated $4 \mathrm{~L}$ flasks and allowed to supernate for $48 \mathrm{~h}^{[9]}$. According to "The Freshwater Algae of China: Systematics, Taxonomy and Ecology" and "Freshwater plankton map", phytoplankton species were identified and counted $^{[10-11]}$. All phytoplankton samples were analyzed by the same investigator. The count was counted twice and the density of the phytoplankton was calculated by the following formula:

$N($ inds $/ L)=\frac{\text { average number }}{80} \times 400 \times 10^{4} \times \frac{3}{50} \times 1000$

After phytoplankton qualitative and quantitative analysis, the phytoplankton community characteristics in Minxin River were analyzed by Dominance index $(Y)$, Shannon-Wiener diversity index $\left(H^{\prime}\right)$, Margalef Species diversity index $(d)$ and Pielou evenness index $(J)$. Assessment criterion of each index were showed in Tab.2. The calculation formula is as follows:

$$
\begin{aligned}
& Y=\frac{N_{i}}{N} \times f_{i} \\
& H^{\prime}=-\sum_{i}^{S} p_{i} \ln p_{i} \quad p_{i}=\frac{N i}{N} \\
& d=(S-1) / \ln N \\
& J=H^{\prime} / \ln \mathrm{S}
\end{aligned}
$$

$N_{i}$ — the number of individuals of the i-th species;

$N$ - the total number of all species; $f_{i}$ is the frequency of the i-th species at each sation;

\begin{tabular}{|c|c|c|}
\hline Index & Range & Criterion \\
\hline$Y$ & $\geq 0.02$ & dominant species \\
\hline \multirow{5}{*}{$H^{\prime}$} & 0 & serious pollution \\
\hline & $0-1$ & heavy pollution \\
\hline & $1-2$ & meso-polluted \\
\hline & $2-3$ & oligo-polluted \\
\hline & $>3$ & clean \\
\hline \multirow{4}{*}{$J$} & $0-0.3$ & heavy pollution \\
\hline & $0.3-0.5$ & meso-polluted \\
\hline & $0.5-0.8$ & oligo-polluted \\
\hline & $>0.8$ & clean \\
\hline \multirow{5}{*}{$d$} & $0-1$ & serious pollution \\
\hline & $1-2$ & heavy pollution \\
\hline & $2-3$ & meso-polluted \\
\hline & $3-4$ & oligo-polluted \\
\hline & $>4$ & clean \\
\hline
\end{tabular}

$S$ - the total number of species.

The evaluation criteria of each index are shown in Tab.2.

Tab.2 Assessment criterion of each index

\section{Results and discussion}

In December 2019, a total of 38 species, 26 genera and 6 phyla of phytoplankton in M River were identified. The composition and percentage of phytoplankton species are shown in Tab.3. Percent composition of different phytoplankton community density in Fig.2. The list of dominant species were showed in Tab.4. Statistical results of phytoplankton community density were showed in Tab.5. The results of Shannon-Wiener diversity index $\left(H^{\prime}\right)$, Margalef Species diversity index $(d)$ and Pielou evenness index $(\mathrm{J})$ were showed in Fig.3. 
Tab.3 Phytoplankton species composition in M River

\begin{tabular}{|c|c|c|c|}
\hline Phyla & Genus(inds) & Species & Percent \\
\hline Bacillariophyta & 8 & 13 & 34.21 \\
\hline Cyanophyta & 7 & 10 & 26.32 \\
\hline Chlorophyta & 7 & 11 & 28.95 \\
\hline Euglenophyta & 2 & 2 & 5.26 \\
\hline Chrysophyta & 1 & 1 & 2.63 \\
\hline Xanthophyta & 1 & 1 & 2.63 \\
\hline Total & 26 & 38 & 100 \\
\hline
\end{tabular}

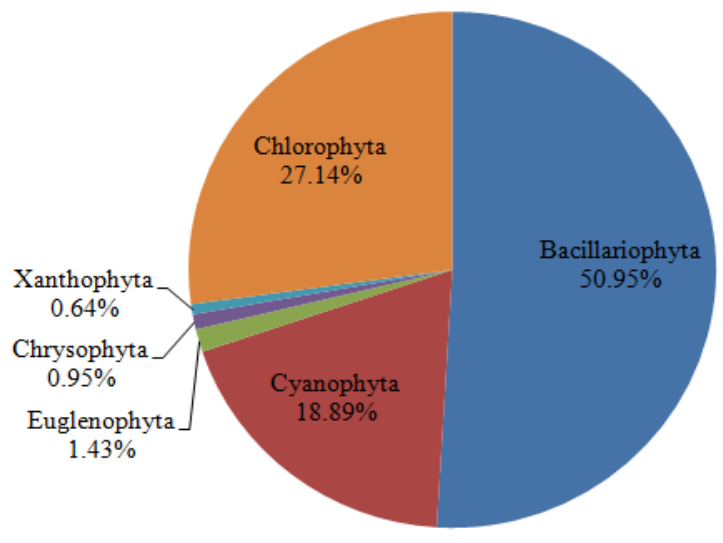

Fig.2 Percent composition of different phytoplankton community density

Tab.4 The list of dominant species

\begin{tabular}{|c|c|c|c|}
\hline Site & $\begin{array}{c}\text { Dominant } \\
\text { species }\end{array}$ & $\begin{array}{c}\text { Occurrence } \\
\text { frequency(\%) }\end{array}$ & $\begin{array}{c}\text { Dominance } \\
\text { index ( })\end{array}$ \\
\hline $\mathrm{S}_{1}$ & Synedra $s p$ & 79.2 & 0.042 \\
\hline $\mathrm{S}_{2}$ & Navicula $s p$ & 74.3 & 0.039 \\
\hline \multirow{2}{*}{$\mathrm{S}_{3}$} & Synedra $s p$ & 81.4 & 0.043 \\
\cline { 2 - 4 } & Oscillatoria $s p$ & 75.2 & 0.039 \\
\hline \multirow{2}{*}{$\mathrm{S}_{4}$} & Nitzschia $s p$ & 73.1 & 0.038 \\
\hline \multirow{2}{*}{$\mathrm{S}_{5}$} & Ulothrix $s p ;$ & 76.3 & 0.040 \\
\hline
\end{tabular}

Tab.5 Statistical results of phytoplankton community density in M River (Unit: inds /L)

\begin{tabular}{|c|c|c|c|c|c|c|c|}
\hline Site & $\begin{array}{c}\text { Total } \\
\text { density }\end{array}$ & $\begin{array}{c}\text { Bacillariophyta } \\
\text { density }\end{array}$ & $\begin{array}{c}\text { Cyanophyta } \\
\text { density }\end{array}$ & $\begin{array}{c}\text { Chlorophyta } \\
\text { density }\end{array}$ & $\begin{array}{c}\text { Euglenophyta } \\
\text { density }\end{array}$ & $\begin{array}{c}\text { Chrysophyta } \\
\text { density }\end{array}$ & $\begin{array}{c}\text { Xanthophyta } \\
\text { density }\end{array}$ \\
\hline $\mathrm{S}_{1}$ & $7.0 \times 10^{6}$ & $4.2 \times 10^{6}$ & $1.2 \times 10^{6}$ & $1.2 \times 10^{6}$ & 0 & $0.4 \times 10^{6}$ & 0 \\
\hline $\mathrm{S}_{2}$ & $7.1 \times 10^{6}$ & $5.1 \times 10^{6}$ & $0.8 \times 10^{6}$ & $0.6 \times 10^{6}$ & $0.4 \times 10^{6}$ & 0 & $0.2 \times 10^{6}$ \\
\hline $\mathrm{S}_{3}$ & $29.1 \times 10^{6}$ & $10.8 \times 10^{6}$ & $8.4 \times 10^{6}$ & $9.6 \times 10^{6}$ & $0.3 \times 10^{6}$ & 0 & 0 \\
\hline $\mathrm{S}_{4}$ & $10.5 \times 10^{6}$ & $6.6 \times 10^{6}$ & $0.9 \times 10^{6}$ & $2.7 \times 10^{6}$ & 0 & $0.2 \times 10^{6}$ & $0.1 \times 10^{6}$ \\
\hline $\mathrm{S}_{5}$ & $9.3 \times 10^{6}$ & $5.4 \times 10^{6}$ & $0.6 \times 10^{6}$ & $3.0 \times 10^{6}$ & $0.2 \times 10^{6}$ & 0 & $0.1 \times 10^{6}$ \\
\hline Total & $63 \times 10^{6}$ & $32.1 \times 10^{6}$ & $11.9 \times 10^{6}$ & $17.1 \times 10^{6}$ & $0.9 \times 10^{6}$ & $0.6 \times 10^{6}$ & $0.4 \times 10^{6}$ \\
\hline
\end{tabular}
species, including Bacillariophyta Synedra sp, Navicula $s p$ and Nitzschia sp, Chlorophyta Ulothrix sp, Cyanophyta Oscillatoria sp.

The composition of phytoplankton species mainly is Bacillariophyta, Cyanophyta and Chlorophyta. Bacillariophyta is the richest species of algae, which accounted for $34.21 \%$ (Tab.3). The percentage of Cyanophyta and Chlorophyta in the number of species was similar, accounted for $26.32 \%$ and $28.95 \%$ (Tab.3), respectively. It can be seen from Tab.5 that the density of Bacillariophyta was the largest at $32.1 \times 10^{6}$, accounting for $50.95 \%$ of the total density of phytoplankton, followed by Chlorophyta (27.14\%) (Fig.2). Bacillariophyta density was greatest at all sampling sites (Tab.5). Therefore, Bacillariophyta not only occupies an advantage in the number of species, but also occupies a certain advantage in density (Tab.3 and Fig.2). The phytoplankton density of $\mathrm{S}_{3}$ is the largest, accounted for $46.19 \%$ of the total phytoplankton, followed by $\mathrm{S}_{4}(16.67 \%)$ and $\mathrm{S}_{5}(14.76 \%)$. The total density of phytoplankton was $63.0 \times 10^{6}$ inds/L. According to the evaluation criteria of lake eutrophication $^{[12]}$, M River belongs to an eutrophic water body, there may be some influence on the composition and distribution of phytoplankton species. In recent years, a large amount of organic pollutants containing nitrogen and phosphorus are discharged into the M River, the degree of water quality eutrophication is aggravated, which directly affects the urban water quality. In general, there is a clear positive correlation between nutrient concentration and biomass in lakes. Algae have some indication effect on water quality ${ }^{[13]}$.

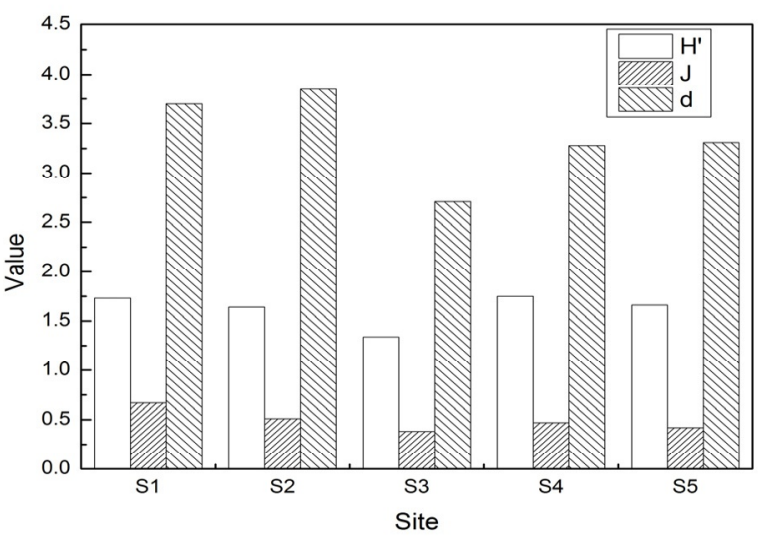

Fig.3 Diversity index of the phytoplankton in M River 
As can be seen from Fig.3, Shannon-Wiener diversity index of all sites were between 1-2, which indicate that the water quality is meso-polluted. Pielou evenness index of $\mathrm{S}_{1}$ and $\mathrm{S}_{2}$ were between 0.5 and 0.8 , which indicate that the river is oligo-polluted, but $\mathrm{S}_{3}, \mathrm{~S}_{4}$ and $\mathrm{S}_{5}$ were mesopolluted whose index in the range of 0.3-0.5. Margalef Species diversity index of all sites were between 3-4, which indicate that the water quality is oligo-polluted, but $\mathrm{S}_{3}$ were meso-polluted whose index were between 2 and 3 . The change trend of Shannon-Wiener diversity index, Margalef Species diversity index and Pielou evenness index are basically consistent, all of which are the lowest in $S_{3}$. This close relationship between them is reflected in ecological processes such as predation, competition and succession ${ }^{[14]}$. Among all the sampling sites, $\mathrm{S}_{3}$ is the most serious pollution. In summary, the M River water quality is meso-polluted.

\section{Conclusions}

The main types of phytoplankton in the M River include Bacillariophyta (34.21\%), Cyanophyta (26.32\%) and Chlorophyta $(28.95 \%)$. The total density is $63.0 \times 10^{6}$ inds/L of phytoplankton, it is indicated that the M River belongs to eutrophic water body. According to the integrative analysis result of Shannon-Wiener diversity index, Margalef Species diversity index and Pielou evenness index, M River water quality belongs to mesopolluted, but individual sites belong to oligo-polluted.

\section{Acknowledgments}

This research was supported by National natural science foundation (41373096), National environmental protection issues (201509041-05), natural science foundation of Hebei Province (B2014208068), Hebei Provincial Environmental Protection Bureau of public issues, Hebei Province pharmaceutical molecular chemistry laboratory open fund and Hebei Province key discipline construction fund project funded.

\section{Reference}

1. He R, Jiang L, Zheng S M, Zhou Y L, Zou S J, Ding S.(2016) Phytoplankton community structure and water quality assessment in Longtan River of ThreeGorges Reservoir. Journal of Hydroecology, (04):3035 .

2. Darchambeau F, Sarmentob H, Descy J.P. (2014) Primary production in a tropical large lake: the role of phytoplankton composition. Sci. Total Environ, 473474, 178-188.
3. Rangel LM, Soares MCS, Paiva R, et al.(2016) Morphology-based functional groups as effective indicators of phytoplankton dynamics in a tropical cyanobacteria-dominated river-reservoir system. Ecological Indicator, 64: 217-227.

4. Katsiapi M, Moustaka-Gouni M, Sommer U. (2016) Assessing ecological water quality of freshwaters: PhyCoI - a new phytoplankton community index. Ecological Informatics, 31:22-29.

5. Wang Y N. (2016) Phytoplankton community characteristics and water quality assessment in the Shanxi Section of Xiaolangdi Reservoir.Journal of Shan Xi Hydrotechnics, (03):123-126.

6. Jin L, Li L Y, Zhou Y, Liu C Q. (2017) Phytoplankton community and water quality analysis of three typical waters in Baiyangdian Lake[J]. Journal of Heibei University (Natural Science Edition), 37 (03) : 329336.

7. Makandar, M.B., Bhatnagar, A. (2010) Biodiversity of microalgae and cyanobacteria from freshwater bodies of jodhpur, Rajasthan (India). J. Algal Biomass Util. 1, 54-69.

8. Gao X, Song J. (2005) Phytoplankton distributions and their relationship with the environment in the Changjiang Estuary, China.[J]. Marine Pollution Bulletin, 50 (3):327-335.

9. $\mathrm{Xu} \mathrm{Y,} \mathrm{Li} \mathrm{A} \mathrm{J,} \mathrm{Qin} \mathrm{J,} \mathrm{et} \mathrm{al.} \mathrm{(2017)} \mathrm{Seasonal} \mathrm{patterns} \mathrm{of}$ water quality and phytoplankton dynamics in surface waters in Guangzhou and Foshan, China. Science of the Total Environment, s 590-591:361-369.

10. Hu H J, Wei Y X. (2006) The freshwater algae of china: systematics, taxonomy and ecology. Science Press, Beijing.

11. Han M S. (1980) Freshwater plankton map[M]. Beijing: Agricultural Press.

12. Jensen, J.P., Jeppesen E, Olrik K, et al. (1994) Impact of nutrients and physical factors on the shift Cyanobacteria to Chlorophytea in shallow Danisk lakes. Canadian Jouranl of Fisheries and Aquatic Sciences, 51: $1692 \sim 1699$.

13. Goda T. (1981) Comprehensive studies on the eutrophication of freshwater areas, XI: summary of researches. The National Institute for Environmental Studies, 27: 61-71.

14. Guo J S, Chen J, Li Z, et al. (2008) Investigation of phytoplankton and assessment of algal diversity on backwater area of Xiaojiang River in Three Gorges Reservoir after its initiate impounding to the water level of $156 \mathrm{~m}$ in spring. Environmental Science, 29(5): 2710-27. 